\title{
Polyamide/MOF bilayered thin film composite hollow fiber membranes with tuned MOF thickness for water nanofiltration
}

Carlos Echaide-Górriz, ${ }^{\mathrm{a}}$ José A. Zapata, ${ }^{\mathrm{a}}$ Miren Etxeberría-Benavides, ${ }^{\mathrm{b}}$ Carlos Téllez, ${ }^{\mathrm{a}}$ Joaquín Coronas ${ }^{\mathrm{a}, *}$

${ }^{a}$ Chemical and Environmental Engineering Department, Instituto de Nanociencia de Aragón (INA), Instituto de Materiales de Aragón (ICMA), Universidad de Zaragoza-CSIC, 50018 Zaragoza, Spain.

b TECNALIA, 20009 Donostia - San Sebastián, Spain.

*Corresponding author: coronas@unizar.es

\section{Abstract}

A bilayered polyamide-MOF membrane was synthesized on the inner surface of a hollow fiber support (200/350 mm ID/OD). The continuous MOF layer was crystallized by liquid phase crystal growth, and after that a polyamide layer was formed by interfacial polymerization on the top of the MOF. Firstly, the influence of time in the crystal growth of the MOF layer (from 15 to 120 min) was studied. The main characteristics of such MOF layer were tested (gas permeance and selectivity, and layer thickness measurements by SEM) to decide which of them were the optimum to support the polyamide thin film. The final bilayered membranes were characterized by SEM imaging and XPS and their performance was established in the nanofiltration of a solution of sunset yellow (450 Da) in water. Both permeance and selectivity were improved compared to a conventional TFC membrane (without the MOF layer): water permeance from 0.06 \pm 0.01 to $0.24 \pm 0.09 \mathrm{~L} \cdot \mathrm{m}^{-2} \cdot \mathrm{h}^{-1} \cdot \mathrm{bar}^{-1}$, and dye rejection from $88 \pm 2.2$ to $98 \pm 0.7 \%$ ).

\section{Keywords}

Polyamide interfacial polymerization, metal-organic framework ZIF-93, bilayered membrane, water nanofiltration, hollow fiber. 


\section{Introduction}

Nanofiltration is a process that aims at separating economically as well as efficiently different mixtures that involve water and organic solvents, together with certain small molecular weight solutes. For this purpose, membranes with different structures have been studied and synthesized, among which, the thin film composite membranes (TFC) stood out the most. The structure of these membranes, which consists of an asymmetric support with a selective thin layer on top, allows to change separately the chemical properties and porosity of both layers [1]. For this reason, many combinations of polymers have been published [2]; some of them as commercial membranes, but also tailor made membranes. Cadotte et al. [3] synthesized the first TFC membrane in 1980 . This pioneering work gave rise to a multitude of studies in which the TFC membranes were modified with certain fillers to enhance their flux, while keeping a high rejection. The new membranes obtained were the so-called thin film nanocomposite membranes (TFN).

Jeong et al. [4] synthesized for the first time in 2007 a TFN membrane, including zeolites with the goal of improving the performance of the TFC membrane in reverse osmosis. Hereon, more nanostructures were combined with TFC membranes, such as: hollow zeolite spheres [5], functionalized $\mathrm{TiO}_{2}$ [6], functionalized multiwalled carbon nanotubes [7], and UZM-5 [8]. Lately, Sorribas et al. [9] studied the combination of MOF (metal-organic framework) nanoparticles and the TFC membranes to observe the effect of these materials on the membranes. The wide specific areas, as well as the organic character of the MOF structures were expected to influence the membrane performance in organic solvent nanofiltration. Later on, Echaide-Górriz et al. [10] studied the effect of other MOF nanoparticles in TFN membranes and other authors studied alternative procedures to fabricate TFN membranes, such as controlled deposition of MOF nanoparticles [11,12], controlled positioning of a MOF monolayer below the polyamide film [13] and layer-by-layer synthesis $[14,15]$. 
However, all these investigations were carried out in flat membrane supports. Other authors studied the application of the interfacial polymerization method of TFC membrane creation in hollow fibers and tubular membranes. Here, two possibilities came up: the synthesis of the thin film on the outer surface and on the lumen of a hollow fiber. Parthasarathy et al. [16] synthesized a PA thin film on the outer surface of a hollow fiber and this was followed by Liu et al. [17], An et al. [18] and Rajaeian et al. [19], who synthesized outer TFN membranes using SAPO-34, ETS4 or $\mathrm{TiO}_{2}$ as fillers. Interestingly, Verissimo et al. [20] synthesized the PA thin film on the inner surface and Ingole et al. [21] recently combined this TFC hollow fiber membrane with $\mathrm{NH}_{2}$-MIL125(Ti) nanoparticles, whose amine group may enhance the compatibility between the nanoparticles and the polyamide layer. This last membrane, though, was not designed for nanofiltration or reverse osmosis, but for dehydration of gas streams.

In this article, we propose a different structure, where a continuous MOF (ZIF-93) layer will be synthesized on the lumen side of a hollow fiber and then, coated with a TFC of polyamide. This means that instead of adding the MOF as dispersed particles into the polyamide thin film to create a composite membrane, a continuous layer of a MOF structure was synthesized and, on the top of it, the polyamide layer was formed. This is a new approach to obtain a nanofiltration membrane that has recently been demonstrated to be very effective in flat membranes ("bilayered PA-MOF membrane") [22]. Besides, in this article, the synthesis method was modified to be suitable for the fabrication of hollow fibers (more productive in terms of $\mathrm{m}^{2} / \mathrm{m}^{3}$ ratio [23]). In the synthesis of the polyamide, a first impregnation with an aqueous solution was carried out. For this reason, a hydrophilic MOF was required. Besides, this MOF should be synthesizable at room temperature and atmospheric pressure. The imidazolate-type MOFs generally meet the second condition, but they usually tend to be rather hydrophobic. However, some of them show a slight hydrophilic character, due to the presence of polar functional groups in the linker. This is the case of ZIF-93, which has an aldehyde group in its structure, thus it meets the two mentioned criteria [24]. Additionally, this aldehyde could react to the amine groups from the monomer to form Schiff bases, which may lead to interesting interactions polyamide-ZIF-93 [25]. Consequently, the ZIF- 
93, previously synthesized by Cacho-Bailo et al. [26] in a P84 ${ }^{\circledR}$ hollow fiber for gas separation, was the chosen MOF to prepare the bilayered PA-MOF membrane.

This research aims at studying the performance of a continuous ZIF-93 structure as a support to synthesize a bilayered PA-MOF membrane to nanofiltrate an aqueous solution. The membranes synthesized by microfluidics on the inner surface of the hollow fiber adopted the name of bilayered or double layer PA-MOF membranes. The synthesis on the lumen is preferred over the outer surface due to the advantages of microfluidics widely reported in literature, such as the high synthesis control, the use of small reagent volumes and its sequential nature [23,27,28]. Their full structure will be characterized in this report.

\section{Experimental}

\subsection{MOF particles synthesis}

ZIF-93 was synthesized following a modified method firstly carried out by Cacho-Bailo et al. [26]. A $0.10 \mathrm{~mol} / \mathrm{L}$ zinc nitrate hexahydrate solution $\left(\mathrm{Zn}\left(\mathrm{NO}_{3}\right)_{2} \cdot 6 \mathrm{H}_{2} \mathrm{O}\right.$, Sigma-Aldrich, $\left.98 \%\right)$ in water was mixed together with a $0.30 \mathrm{~mol} / \mathrm{L}$ 4-methyl-5-imidazolecarboxaldehyde $\left(\mathrm{C}_{5} \mathrm{H}_{6} \mathrm{~N}_{2} \mathrm{O}\right.$, Across-Organics, 99\%) and $0.30 \mathrm{~mol} / \mathrm{L}$ sodium formiate (NaCOOH, Sigma-Aldrich, $>99 \%)$ solution in methanol (Scharlab, 99.9\%).

\subsection{MOF particles characterization}

Thermogravimetric analysis (TGA) was used to evaluate the thermal stability of the ZIF-93 structure and the correct activation of its porosity. The measurements were taken in a Mettler Toledo TGA/SDTA 851e system, using an atmosphere of air and a heating rate of $10{ }^{\circ} \mathrm{C} / \mathrm{min}$, until $700^{\circ} \mathrm{C}$.

The crystallinity of the MOF was characterized by X-ray diffraction analysis (XRD). The equipment used was a D-Max 2500 Rigaku diffractometer with a $\mathrm{Cu} \mathrm{K} \alpha(\lambda=0.1542 \mathrm{~nm})$ rotating anode. The measurements were taken from 4 to $40^{\circ}(2 \theta)$ with a $0.025^{\circ} \cdot \mathrm{s}^{-1}$ step, operating at 40 $\mathrm{kV}$ and $80 \mathrm{~mA}$. 
Nitrogen adsorption analysis was necessary to obtain the ZIF-93 specific surface area, calculated by the Brunauer-Emmett-Teller (BET) method. The experiments took place at $77 \mathrm{~K}$ under variable relative pressure. The equipment used was a Micrometrics Tristar 3000. The degasification before the nitrogen adsorption experiment took place at $200{ }^{\circ} \mathrm{C}$ for $8 \mathrm{~h}$.

\subsection{Polyimide hollow fibers}

The hollow fibers used in this work were made of the polyimide P84 ${ }^{\circledR}$. The synthesis of these hollow fibers has been detailed in previous publications $[26,29]$. In the case of this research they had a length of $16 \mathrm{~cm}$, an inner diameter of $200 \mu \mathrm{m}$ and an outer diameter of $350 \mu \mathrm{m}$.

\subsection{Membranes synthesis}

TFC membrane. The synthesis of the polyamide thin film on the inner surface of the hollow fiber supports (see Fig. 1A below to observe the scheme of its structure) was carried out at room temperature, following the method in ref. [20]. Nevertheless, some parameters, such as the concentrations and the contact times were different in the synthesis presented here. Firstly, an aqueous m-phenylenediamine (MPD, $99 \%$, Sigma - Aldrich) solution of $2 \%(w / v)$ was pumped through the lumen side for $5 \mathrm{~min}$ at a rate of $70 \mu \mathrm{L} / \mathrm{min}$. Secondly, pure cyclohexane (Scharlab, extra pure) was pumped at a rate of $157 \mu \mathrm{L} / \mathrm{min}$ for $1 \mathrm{~min}$, so the excess solution of MPD that did not diffuse into the superficial pores of the support was removed. Finally, a solution of $0.3 \%(\mathrm{w} / \mathrm{v})$ of trimesoyl chloride (TMC, 98\%, Sigma - Aldrich) in n-hexane (Scharlab, extra pure) was pumped at a rate of $70 \mu \mathrm{L} / \mathrm{min}$ for $1.5 \mathrm{~min}$. This last step was continued by a washing procedure with cyclohexane first, and deionized water afterwards.

MOF-based membrane. The synthesis procedure was based on a microfluidic strategy similar to the carried out in ref. [26] at room temperature. Two solutions, one of $0.10 \mathrm{~mol} / \mathrm{L} \mathrm{Zn}\left(\mathrm{NO}_{3}\right)_{2} \cdot 6 \mathrm{H}_{2} \mathrm{O}$ in water and the other of $0.30 \mathrm{~mol} / \mathrm{L} \mathrm{C}_{5} \mathrm{H}_{6} \mathrm{~N}_{2} \mathrm{O}$ and $0.30 \mathrm{~mol} / \mathrm{L} \mathrm{NaCOOH}$ in methanol, were mixed while going through the lumen of the polyimide hollow fiber to obtain the structure shown in Fig. 1B. In the work of Cacho-Bailo et al. [26], this synthesis took place for $80 \mathrm{~min}$. However, the 
synthesis time was modified here $(15,30,80,100$ and $120 \mathrm{~min})$ to observe its effect in the final MOF layer thickness and, therefore, in the bilayered PA-MOF membrane performance.

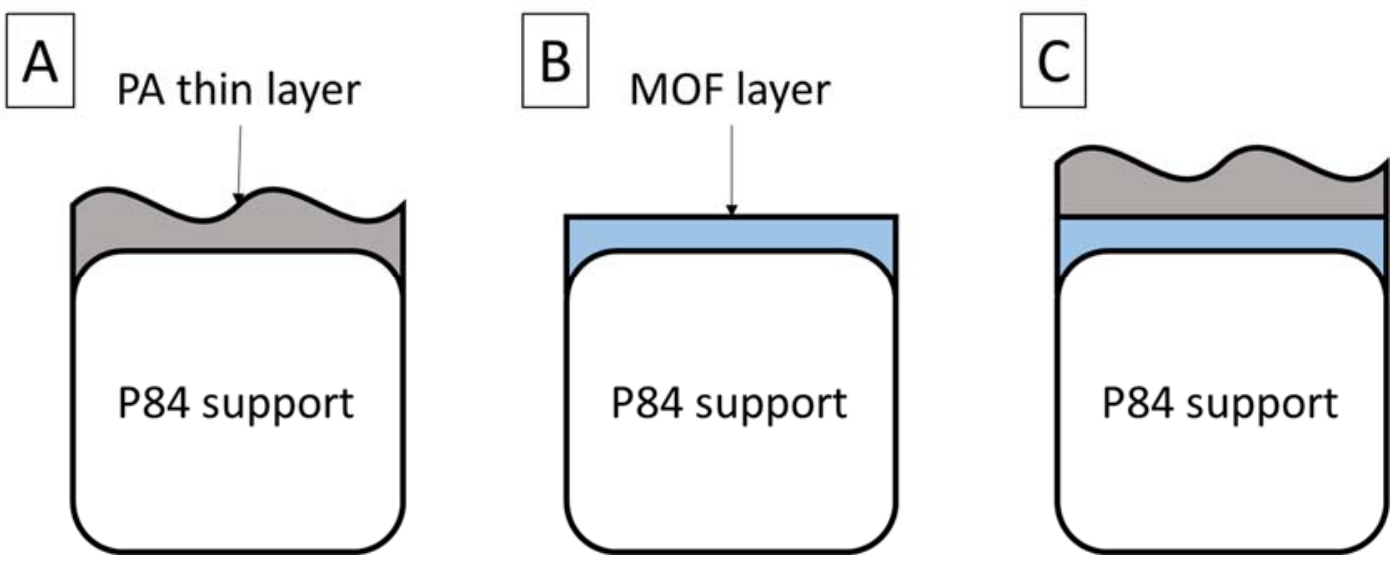

Fig. 1. Structures of the three membranes synthesized: the TFC membrane, composed by the polyimide P84 $^{\circledR}$ support and the PA thin film, with an estimated average surface roughness value of $15 \mathrm{~nm}$ [22] (A); the MOF-based membrane, composed by a continuous MOF layer formed on the polyimide P84 ${ }^{\circledR}$ support (B); and the double layer PA-MOF; formed by the PA thin film over the MOF layer, synthesized on the polyimide P84 ${ }^{\circledR}$ support, with an estimated average roughness value of $38 \mathrm{~nm}[22]$ (C).

Double layer PA-MOF. The synthesis in this case consisted of the synthesis of a MOF-based membrane, followed by the synthesis of the PA, applying an intermediate washing procedure with deionized water. This gave rise to a membrane with both layers supported on the polyimide hollow fiber, see Fig. 1C. Only the MOF based membrane with the thinnest MOF layer from those synthesized above (depending on the synthesis time) was chosen to be converted into the double layer PA-MOF upon the interfacial polymerization of PA.

\subsection{Membranes characterization}

Scanning electron microscopy (SEM) was used to observe the different MOF layer thicknesses and morphologies of the MOF-based membranes, in addition to the other two types of membranes fabricated (TFC membrane and the double layer PA-MOF). The images were taken top (lumen surface of the samples) and cross-section perspectives. To reveal the lumen surface of the samples, the hollow fibers were cut with an approximate angle of $45^{\circ}$ between the cutting direction 
and the axial axis. To observe the cross-section, a piece of hollow fiber was broken by cryogenic treatment. A FEI-Inspect F20 microscope was used at an acceleration voltage between 10 and 20 $\mathrm{kV}$ with spots of 2.5 and $3.5 \mathrm{~nm}$.

Energy-dispersive X-ray (EDX) was used to evaluate the depth of the ZIF-93 continuous layer into the porosity of the $\mathrm{P} 84^{\circledR}$ support. This layer could be distinguished from the polyamide and the polyimide because of the presence of $\mathrm{Zn}$ in its structure. The microscope used here was the same as the used for the SEM imaging.

XPS experiments were conducted to quantify the amount of carbon $(\mathrm{C})$, oxygen $(\mathrm{O})$ and nitrogen $(\mathrm{N})$ in the lumen of both PA-P $84^{\circledR}$ and bilayered PA-ZIF-93 membranes. The ratios $\% \mathrm{C} / \% \mathrm{~N}$ and $\% \mathrm{O} / \% \mathrm{~N}$ give an estimation of the degree of cross-linking in the polymer [30]. XPS characterization was performed with a Kratos Axis Ultra spectrometer, using a monochromatic $\mathrm{Al} \mathrm{K \alpha}(1486.6 \mathrm{eV}) \mathrm{X}$-ray source at $10 \mathrm{~mA}$ and $15 \mathrm{kV}$ and a power of $150 \mathrm{~W}$. The samples were first evacuated at room temperature (pressures near $10^{-11}$ bar were observed during surface analysis) and analyzed in $0.11 \times 0.11 \mathrm{~mm}^{2}$ areas under the same conditions.

\subsection{Gas permeance tests}

An $\mathrm{H}_{2} / \mathrm{CH}_{4}$ equimolar mixture was fed inside the membrane module at $20 \mathrm{~cm}^{3}(\mathrm{STP}) / \mathrm{min}$ to measure the permeance of the ZIF-93 based hollow fiber membrane synthesized in $120 \mathrm{~min}$. A sweep gas was (He at $\left.10 \mathrm{~cm}^{3}(\mathrm{STP}) / \mathrm{min}\right)$ provided the necessary driving force for permeating the gases across the membrane (pressure drop was always zero). Permeance values in $\mathrm{mol} \mathrm{m}^{-2} \mathrm{~s}^{-1} \mathrm{~Pa}^{-}$

${ }^{1}$ were calculated using the log-mean partial pressure difference along the hollow fiber. Gas separation factors $(\alpha)$ were calculated as the ratio of permeance values. The $120 \mathrm{~min}$ membrane was selected among all the synthesized because its morphology (apparent crystal intergrowth and layer thickness) was the closest to the obtained by Cacho-Bailo et al. [26]. 


\subsection{Nanofiltration}

Firstly, the bare hollow fiber supports were measured in nanofiltration at 8 bar of feed pressure and $20{ }^{\circ} \mathrm{C}$ of temperature, with a solution of $15 \mathrm{mg} / \mathrm{L}$ sunset yellow (SY, $450 \mathrm{Da}-90 \%$ dye content, Sigma Aldrich) in deionized water. The measurements of the TFC membranes and double layer PA-MOF membranes were carried out at the same conditions of pressure, temperature and feed dye content. However, a different feed solution of $15 \mathrm{mg} / \mathrm{L}$ acridine orange (AO, $260 \mathrm{Da}-$ $55 \%$ dye content, Across-Organics) in deionized water was used to perform the nanofiltration tests with the MOF based membranes.

In all cases, the membrane performances were characterized by measuring the water permeance (see Equation 1 below), and analyzing the solute concentration in both retentate and permeate to calculate the rejection (see Equation 2 below). A UV-Vis spectrometer Jasco V-670 was used to obtain the SY and AO concentrations at $380 \mathrm{~nm}$ and $291 \mathrm{~nm}$, respectively, as wavelengths of maximum absorbances.

$$
\begin{gathered}
\text { Permeance }=\frac{Q}{\Delta P}=\frac{V}{A \cdot t \cdot \Delta P} \quad(\text { Equation 1) } \\
\text { Rejection }(\%)=\left(1-\frac{C_{\text {permeate }}}{C_{\text {feed }}}\right) \cdot 100 \quad \text { (Equation 2) }
\end{gathered}
$$

\section{Results discussion}

\subsection{MOF characterization}

Crystalline structure of MOF ZIF-93 (rho type) was confirmed by XRD analysis (Fig. S1A). No other ZIF phases than the expected can be seen in the XRD pattern and they are in agreement with the simulation pattern [31]. According to the TGA analysis (Fig. S1B), the thermal stability of the structure reaches around $300{ }^{\circ} \mathrm{C}$, showing mass losses at temperatures of $100{ }^{\circ} \mathrm{C}$ and below due to the presence of water molecules when the drying is not properly carried out. The nitrogen adsorption isotherm (Fig. S1C) corresponds to the typical microporous structure (type I isotherm), with a hysteresis related to the capillary condensation in spaces between particles [32]. Through 
the Brunauer-Emmett-Teller method, the obtained BET specific surface area was $737 \pm 11 \mathrm{~m}^{2} / \mathrm{g}$. Additionally, it is known from literature that the pore size of ZIF-93 is $3.6 \AA$ [33].

\subsection{Membrane characterization}

To control the thickness of the MOF layer, the concentration of the metal salt in water was reduced from the $0.15 \mathrm{~mol} / \mathrm{L}$ used by Cacho-Bailo et al. [26], to $0.10 \mathrm{~mol} / \mathrm{L}$. Additionally, the synthesis time was modified from 15 to $120 \mathrm{~min}$, studying other duration times such as 30,80 and $100 \mathrm{~min}$. The SEM images of the cross-section in the different times are shown in Figs. 2A, B, C, D and E. The quantification of the thickness depending on the reaction times are shown in Fig. 2F. As the synthesis time decreased, the thickness of the MOF layer also diminished. Moreover, lowering the metal salt concentration and keeping the synthesis time constant produced a reduction in the ZIF-93 layer thickness. Cacho-Bailo et al. [26] carried out the synthesis for $80 \mathrm{~min}$, obtaining a layer of $2.6 \pm 0.4 \mu \mathrm{m}$, thicker than the $0.96 \pm 0.5$ obtained in this article (see Fig. $2 \mathrm{~F}$ ). In principle, the reaction time might have influenced the intergrowth of the MOF crystals and the molecular selectivity could be lower in a MOF layer synthesized for $15 \mathrm{~min}$ than for $120 \mathrm{~min}$. However, the goal of the MOF layer is not the solute rejection, but the water permeance enhancement in the final double layer PA-MOF. Therefore, it is the PA which is the actual selective layer in this membrane. 


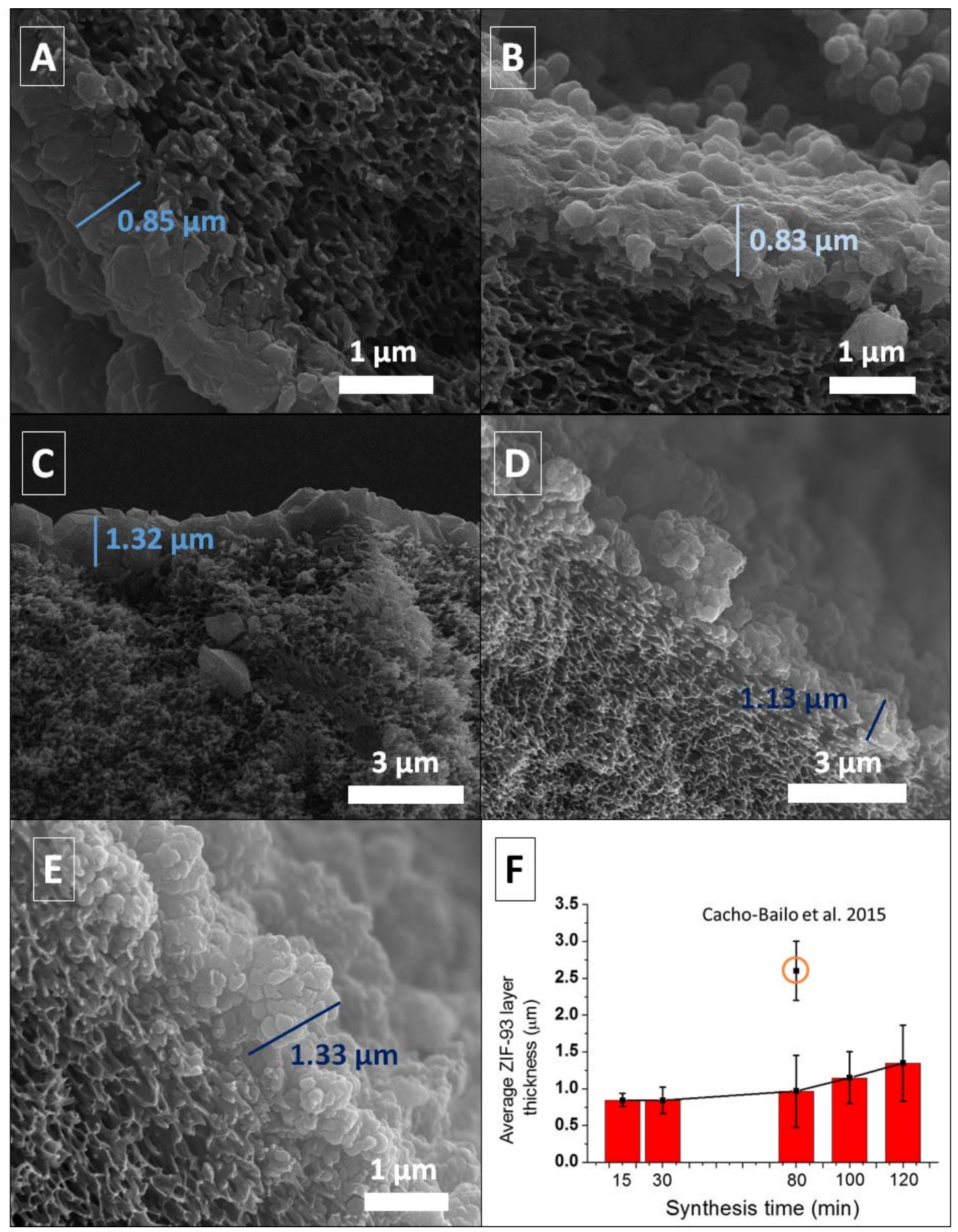

Fig. 2. Cross-section of MOF-based hollow fiber membranes with synthesis times of $15 \mathrm{~min}(\mathrm{~A}), 30 \mathrm{~min}$ (B), $80 \mathrm{~min}$ (C), 100 min (D) and 120 min (E). Thicknesses obtained from the SEM images (F). Value of Cacho-Bailo et al. 2015 obtained from [26].

There are several reports where the ligand/metal molar ratio was modified for the synthesis of a certain MOF, although not many of them are related to ZIF-93. For instance, Jian et al. [34] carried out several experiments to observe the effect of the ligand/metal molar ratio in the ZIF-8 morphology, maintaining reaction yields above $90 \%$ in all cases. They observed that as the ratio 
decreased, the particles formed tended to be less crystalline. In the current work, we have increased the ratio (from 2:1 to 3:1), but modifying the metal content instead of the ligand content. Consequently, we have also increased the solvent/metal ratio, which might have lowered the reaction yield. As a result, the MOF layer obtained here after $120 \mathrm{~min}$ of synthesis time is thinner than the obtained by Cacho-Bailo et al. [26] after $80 \mathrm{~min}$. Along with this morphology difference, the ZIF-93 layer we obtained may have some defects, in agreement with the fact that its $\mathrm{H}_{2} / \mathrm{CH}_{4}$ selectivity was lower than the obtained by Cacho-Bailo et al. at either $35^{\circ} \mathrm{C}$ or $180{ }^{\circ} \mathrm{C}$ (see the inset of Fig. 3) [26]. However, the current ZIF-93 membrane resulted to be ten times more $\mathrm{H}_{2}$ permeable than the obtained by Cacho-Bailo et al. [26]. The positive effect of temperature in $\mathrm{H}_{2}$ permeance and $\mathrm{H}_{2} / \mathrm{CH}_{4}$ selectivity in a MOF-based hollow fiber membrane was previously observed in a study conducted by Hara et al. [35]. Analyzing the performance of a ZIF-8-based membrane, they evidenced a higher apparent activation energy $\left(E_{a}\right)$ for $\mathrm{H}_{2}$ permeation than for $\mathrm{CH}_{4}\left(1.36\right.$ and $0.12 \mathrm{~kJ} / \mathrm{mol}$, respectively), and therefore the enhancement of the $\mathrm{H}_{2} / \mathrm{CH}_{4}$ selectivity as a function of temperature. In that case, the membrane consisted of a continuous layer of ZIF-8 on an alumina support, instead of ZIF-93 supported on a polymeric hollow fiber as fabricated here; but it can be representative of the gas permeance dependence with temperature, due to the structural similarities between both MOFs. 


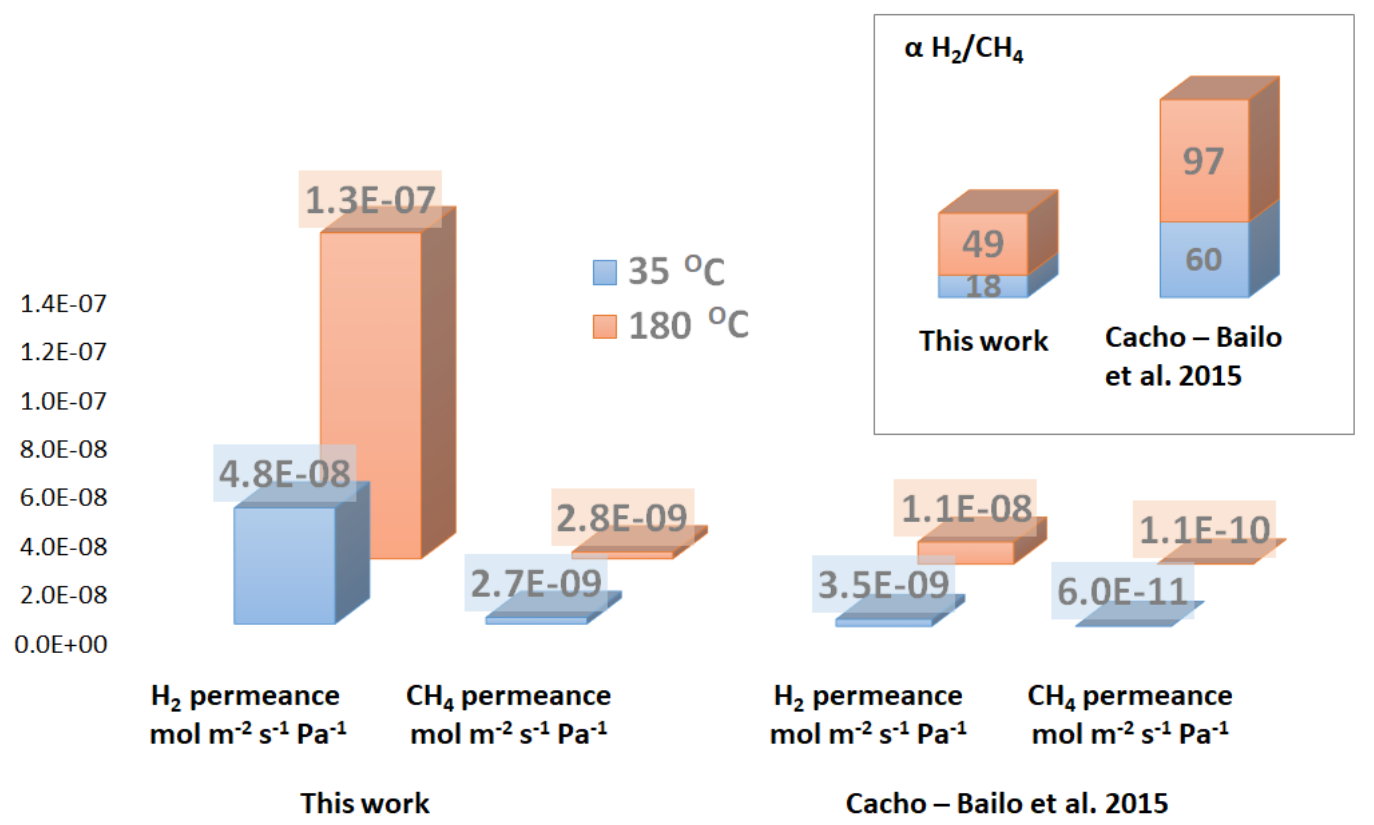

Fig. 3. $\mathrm{H}_{2} / \mathrm{CH}_{4}$ permeation comparison, carried out at 35 and $180{ }^{\circ} \mathrm{C}$, between the ZIF-93-based hollow fiber membrane synthesized here during 120 min and the ZIF-93 based hollow fiber membrane synthesized by Cacho-Bailo et al. [26] during $80 \mathrm{~min}$.

At lower synthesis times (15 and $30 \mathrm{~min})$, the effect of time in the MOF layer thickness was apparently negligible. In this way, it would be more efficient to carry out the 15 min synthesis to obtain the double layer PA-MOF membrane (since a lower amount of reactants was needed to obtain the same membrane).

The polyimide P84 ${ }^{\circledR}$ support shows a homogeneous morphology formed by pores of around 500 $\mathrm{nm}$ all over the inner surface (see Fig. 4A). When a TFC membrane is formed, the polyimide surface is fully covered by the PA, as shown in Fig. 4B. Due to the sample preparation, the PA layer detached from the support in Fig. 4B gives an idea of how both structures contact each other after the synthesis. Besides, the inset in Fig. 4B (Fig. 4b) allows an estimation of the thin layer thickness of $57 \pm 10 \mathrm{~nm}$. 


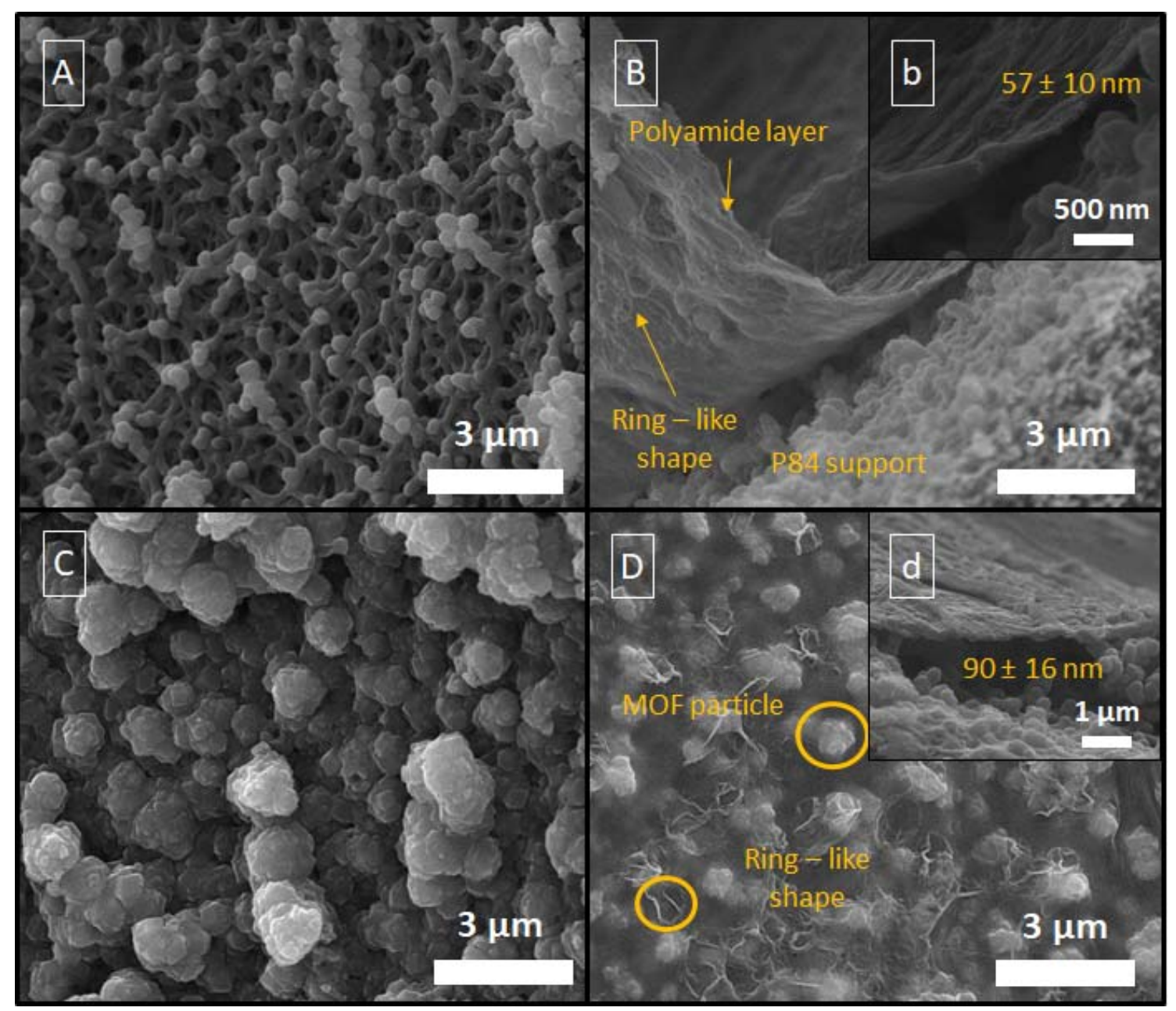

Fig. 4. Bare P84 ${ }^{\circledR}$ hollow fiber support inner surface (A); TFC membrane with the PA thin film synthesized on the lumen side of the polyimide $P 84^{\circledR}$ support (B) and a view in higher magnification of the thin layer cross-section with its average thickness indicated (b); MOF-based membranes supported on the inner surface of the P84 ${ }^{\circledR}$ support (C), and double layer PA-MOF membrane supported on the inner surface of the P84 ${ }^{\circledR}$ support (D), where the same MOF layer observed in $C$ is covered by a continuous PA layer. In the inset, the cross-section is observed and the average PA thin film thickness is indicated (d).

Fig. 4C shows a continuous layer of MOF ZIF-93 covering the support. This structure, similar to that previously synthesized by Cacho-Bailo et al. [36] in this type of hollow fiber, covers completely the support surface with a layer of around $1 \mu \mathrm{m}$ of thickness. As Fig. S2A depicts, the MOF structure might have crystallized also inside the most superficial pores. The inset of this figure shows that the ZIF-93 grew wrapping the superficial P84 ${ }^{\circledR}$ polymer fragments. In several previous studies, the MOF layer was synthesized by interfacial synthesis (IMMP, for instance, developed by Brown et al. [37]), leading to a continuous layer which barely penetrated inside the 
porous structure of the support. However, other authors, such as Marti et al. [38] and Cacho-Bailo et al. [27] did not carry out an interfacial synthesis, but they performed a first crystallization inside the porosity, that as Marti et al. [38] indicated, helped anchor the MOF layer onto the support.

Finally, Fig. 4D shows the combination of the MOF and PA layers. The continuous ZIF-93 layer can be easily observed by naked eye, covered with the ring-like shapes typical of PA skin layers. In previous studies, this film was demonstrated to be around $100 \mathrm{~nm}$ thick [9]. In fact, this PA film seems to be so thin that the MOF particles can be observed through it. As can be seen in Fig. $\mathrm{S} 2 \mathrm{~B}$, the PA seems to cover the MOF layer as a blanket, leaving a little empty space in between. The presence of aldehyde groups in the ZIF-93 may give rise to an addition reaction of the amine groups of the PA monomer MPD with the ZIF-93 carbonyls [25]. This reaction has been used to functionalize ZIF-93 [39] and other MOFs that have been applied to produce TFN membranes with enhanced ZIF-PA interaction [21].

Fig. 4d (the inset in Fig. 4D) offers a view with higher magnification of the PA thin film crosssection. According to the thickness estimation, the PA thin film seems to be slightly thicker when it was synthesized on the MOF layer than directly on the P84 ${ }^{\circledR}$ support $(90 \pm 16 \mathrm{~nm}$ compared to $57 \pm 10 \mathrm{~nm}$ ). This does not mean that the first would give more resistance to water transport than the second, since the MOF presence can make the polymeric layer looser by reducing the degree of cross-linking of the polymer [10,30].

\subsection{Nanofiltration}

The bare $\mathrm{P} 84^{\circledR}$ hollow fiber support gave a permeation of $0.57 \mathrm{~L} \cdot \mathrm{m}^{-2} \cdot \mathrm{h}^{-1} \cdot \mathrm{bar}^{-1}$ and a rejection of $75 \%$ (see Fig. 5). The permeance value was reduced to $0.07 \pm 0.01 \mathrm{~L} \cdot \mathrm{m}^{-2} \cdot \mathrm{h}^{-1} \cdot \mathrm{bar}^{-1}$ in the TFC membrane because of the extra transport resistance given by the PA layer, although here the rejection was enhanced from $75 \%$ to $88 \pm 2 \%$. With the addition of the MOF layer, and therefore forming the bilayered PA-ZIF-93 membrane, the water permeance raised to $0.24 \pm 0.09 \mathrm{~L} \cdot \mathrm{m}^{-2} \cdot \mathrm{h}^{-}$

${ }^{1} \cdot$ bar $^{-1}$. The enhancing effect of a composite membrane with the MOF layer below the PA was previously studied by Wang et al. [15] However, in our work, apart from the permeance 
enhancement, also the solute rejection was increased compared to the TFC membrane ( $97.5 \pm 0.7$ $\%$ in contrast to $88 \pm 2 \%$ ). Besides, Fig. S3 compares the performances of the ZIF-93-based membrane (no polyamide on top) and the bilayered PA-ZIF-93 membrane. The bare MOF layer gave rise to lower water permeance but a slightly higher solute rejection (AO in this case). This is explained by the adsorption of AO by ZIF-93. In fact, ZIF-93 powder can adsorb ca. $0.02 \mathrm{mg}$ $\mathrm{AO} / \mathrm{g}$ after $96 \mathrm{~h}$ at room temperature $(3 \mathrm{~mL}$ of $15 \mathrm{mg} / \mathrm{L}$ in contact with $440 \mathrm{mg}$ of MOF with no stirring).

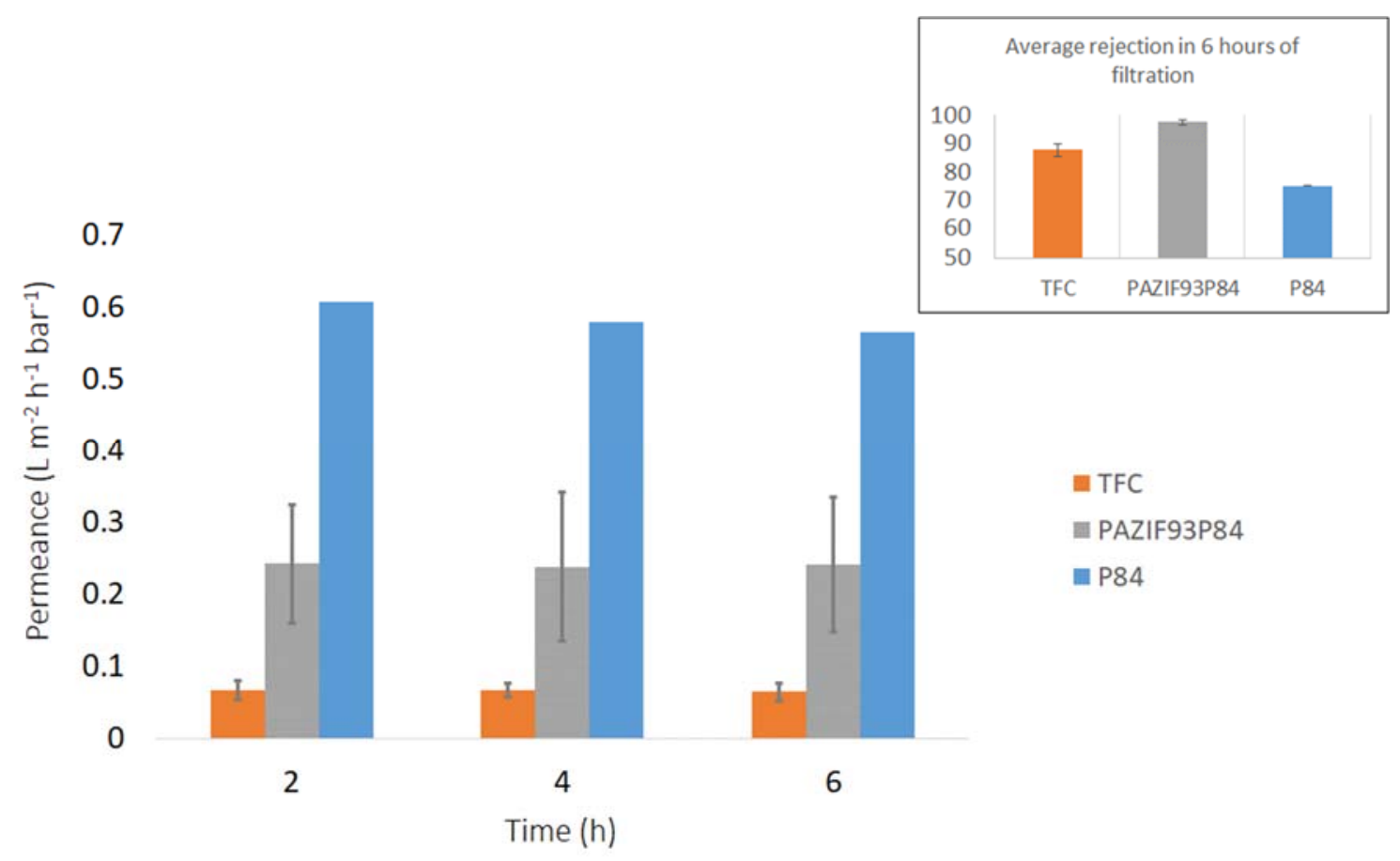

Fig. 5. Nanofiltration performances of the TFC membrane (orange), double - layer PA-ZIF-93, with the MOF layer synthesized in 15 min (grey), and bare P84 ${ }^{\circledR}$ support (blue) in a SY-water solution filtration (see the ZIF-93-based membrane performance in Fig. S3). The main graph shows the permeability of each type of membrane vs the hours of filtration. The graph at the top (inset) shows the average rejection of the solute during the $6 \mathrm{~h}$ of the permeability test for each type of membrane.

Next, some explanations are given about why the two superposed PA-ZIF-93 layers provoke an enhancement of permeance in the bilayered membrane as compared to a composite membrane with one single thin layer of PA (TFC). The most commonly considered effects deal with the influence of the MOF particles in the PA cross-linking degree $[15,30]$, the changes in the 
hydrophilicity of the most superficial membrane surface $[9,10,15]$ and the creation of voids in the controlling PA ultrathin layer [10]. Moreover, other phenomena, such as the PA layer roughness enhancement due to the presence of MOFs must be considered.

Both the PA cross-linking degree modification by the presence of MOF particles and the hydrophilicity changes in the most superficial layer of the membrane are realistic causes for the enhancement of water permeance. Duan et al. and some other authors previously observed the first phenomenon $[10,30]$ and Paseta et al. did observe changes in the hydrophilic character of the polyamide specifically in the case of bilayered PA-ZIF-93 membranes, although they were less intense than when the ZIF-93 particles were embedded in the PA. However, since the continuous MOF layer is placed under the PA film (i.e. with no filler particles distributed in such film), the creation of voids inside the PA could be neglected. Paseta et al. [22] also observed the influence of the MOF layer below the PA layer in the bilayered membrane roughness (from $15 \mathrm{~nm}$ of the PA supported directly on the polymeric substrate to $38 \mathrm{~nm}$ of the PA supported on the MOF continuous layer), which would turn into a water permeance enhancement. When it comes to the increase in SY rejection, though, the most intuitive reason might be related to the fact that two potentially selective layers are added in series: the PA film is already demonstrated to be selective to this solute [10] and the ZIF-93 is known to have micropores of $0.36 \mathrm{~nm}$ [23] and hydrophilic character as compared to other MOFs.

Duan et al. [30] observed that the presence of ZIF-8 in a TFN membrane enhanced the permeance of water through TFN membranes by reducing the PA cross-linking degree during its polymerization. They evidenced this phenomenon when comparing the $\% \mathrm{C} / \% \mathrm{~N}$ and $\% \mathrm{O} / \% \mathrm{~N}$ element ratios of TFC and TFN membranes with different ZIF-8 amounts. According to them, the presence of the ZIF-8 nanoparticles would decrease the diffusion of MPD molecules to the surface by restricting their pathways, reducing their concentration at the interface, and therefore the PA formation rate and the cross-linking degree.

Wang et al. [15] mentioned the same cross-linking reduction as Duan et al. [30], but this time in a layer-by-layer (LBL) fabrication of PA-ZIF-8 membranes. Here, the reason for this reduction 
was that the hydrophobic ZIF-8 layer hindered the MPD to diffuse and react with the TMC. The authors also observed by FTIR that the ZIF-8 ligand could have reacted with the acyl chloride groups of the TMC molecules, competing with the TMC-MPD reaction, and therefore reducing the cross-linking degree. Besides, Wang et al. [15] mentioned that the chemical interactions between the ZIF- 8 and the PA monomers would leave unreacted carboxylic groups that would increase the contact angle of the PA-ZIF-8 membrane compared to that with only ZIF-8.

In contrast to these evidences, XPS quantification of $\mathrm{C}, \mathrm{N}$ and $\mathrm{O}$ elements shows slightly lower $\% \mathrm{C} / \% \mathrm{~N}$ and $\% \mathrm{O} / \% \mathrm{~N}$ ratios in the PA layer of the bilayered membrane than in the TFC (see Table 1). This suggests a higher cross-linking degree of the PA layer synthesized on the MOF layer as compared to the PA layer synthesized on the support itself. The reason may be related to the aldehyde group of ZIF-93, which might increase the retention of the amine solution because of its interaction with water. In fact, the increase of amine solution quantity taken into the ZIF-93 pores (as well as the aldehyde-amine groups reaction above mentioned) could reduce the competitiveness of the ZIF-93 ligand with the TMC during the polymerization, as stated by Wang et al. [15]. Besides, knowing that the MOF structure is not embedded into the PA layer itself, the cross-linking reduction phenomenon mentioned by Duan et al. should not take place. [30]. All in all, this enhancement of the cross-linking degree would explain the increase in SY rejection when the MOF is part of the membrane structure, but it does not explain the permeance increase.

In this sense, Van Goethem et al. [40] investigated the effect of MOF particles in TFN membranes with ZIF-8 evidencing some interesting phenomena. As they discussed, $\mathrm{HCl}$ is produced during the polymerization. Imidazolate-type MOFs are relatively sensitive to acids and bases and the $\mathrm{pH}$ in the interface boundaries could be low enough to degrade part of the MOF external structures. Consequently, some $\mathrm{Zn}^{2+}$ would have been released. As they observed, these zinc ions seem to enhance the TMC-MPD reaction, so the cross-linking degree would increase as well, instead of decrease. However, the effect of $\mathrm{Zn}^{2+}$, according to Van Goethem et al., is a water permeation enhancement, in spite of the increase of the cross-linking degree [40]. This is interesting, since Table 1 shows a similar phenomenon. When adding a ZIF-93, with $\mathrm{Zn}$ atoms in its structure, the 
cross-linking degree increased, and so did the water permeation (Fig. 5). Consequently, as they said, the most probable consequence of adding zinc ions might be a decrease of the PA thin film thickness, which would reduce the water diffusion resistance and increase the water permeance [40]. However, this is not in agreement with our thickness measurements, since as shown in Figs. 4B and 4D, the PA thickness is lower when made on the ZIF-93 than when made directly on the polyimide support was placed below: $57 \pm 10 \mathrm{~nm}$ versus $90 \pm 16 \mathrm{~nm}$. In addition, the actual values could be lower than these due to the fact than SEM and TEM produced greater thickness measures compared to other techniques such as atomic-force microscopy, Rutherford backscattering spectrometry, quartz crystal microbalance, profilometry and ellipsometry [41].

Table 1. $\% \mathrm{C} / \% \mathrm{~N}$ and $\% O / \% N$ ratios obtained through the quantification of $\mathrm{C}, \mathrm{N}$ and $\mathrm{O}$ elements in XPS of the surface of the bilayered membrane PA-ZIF93 and the TFC membrane. The surfaces considered were of $110 \times 110 \mu m^{2}$

\begin{tabular}{|c|c|c|}
\hline Membrane & $\% \mathrm{C} / \% \mathrm{~N}$ & $\% \mathrm{O} / \% \mathrm{~N}$ \\
\hline PA-ZIF93-P84 & $6.2 \pm 0.6$ & $1.2 \pm 0.1$ \\
\hline TFC & $6.9 \pm 0.7$ & $1.3 \pm 0.1$ \\
\hline
\end{tabular}

Summing up, the ZIF-93 role seems not to be the same as that of ZIF-8 in previous publications [15,30]. In fact, it caused an opposite effect (increase of cross-linking degree in the PA layer), probably due to the chemical differences between both MOFs (aldehyde group in ligand of ZIF93). Moreover, the ZIF-93 might have also contributed to an increase in the hydrophilicity of the PA-ZIF-93 membrane at the same time as an enhancement of the sieving power of the bilayered membrane. Besides, the partial degradation of the MOF structure during the polymerization, which would have released $\mathrm{Zn}^{2+}$, seems to decrease the thin film thickness justifying an enhancement of the water permeation, in spite of the cross-linking degree increase.

\section{Conclusions}

According to the characterization, the PA-ZIF-93 bilayered membrane seems to be successfully synthesized with good PA-MOF interaction enhanced by a possible amine (from interfacial polymerization monomer)-carbonyl (from ligand aldehyde) addition reaction. The experimental conditions (particularly the time, reduced from 80 to $15 \mathrm{~min}$, for the crystallization of ZIF-93) 
were tuned to produce a continuous layer of MOF with higher permeance than in previous reports. In consequence, the nanofiltration experiments showed that this new structure enhanced both the water permeance and dye rejection compared to the TFC membrane and the bare support, in the following order for permeance and rejection, respectively: bare support > ZIF-93-based membrane $>$ PA-ZIF-93 > TFC and PA-ZIF-93 > ZIF-93-based membrane (with an adsorption effect of $\mathrm{AO}$ on the ZIF-93) $>$ TFC $>$ bare support. Although a polyamide cross-linking reduction seems to be usual in the synthesis of composite membranes combined with MOFs, the PA-ZIF93 apparently have not experienced it. In fact, the presence of MOF ZIF-93 contributed to the increase of solute rejection, in combination with an increase of the sieving power of the bilayered membrane with two highly selective materials (the hydrophilic ZIF with pores of ca. $0.36 \mathrm{~nm}$ and the PA able to act as reverse osmosis material). In parallel, zinc ions released from a slight degradation of the MOF structure during the interfacial polymerization might have increased the water permeation because of the decrease of the PA thin film thickness, even though the crosslinking degree increased. These positive effects are remarkable, since the rejection usually diminishes a little in TFN membranes when certain nanoparticles are added in relatively high concentrations to the polyamide synthesis.

\section{Acknowledgements}

Financial support from the Spanish MINECO and FEDER (MAT2016-77290-R), the Aragón Government (T43-17R) and the ESF is gratefully acknowledged. C. Echaide-Górriz thanks the Aragón Government for his $\mathrm{PhD}$ grant. All the microscopy work was done in the Laboratorio de Microscopías Avanzadas at the Instituto de Nanociencia de Aragón (LMA-INA). The authors acknowledge the LMA-INA for offering access to their instruments and expertise.

\section{Bibliography}

[1] S. Hermans, H. Marien, C. Van Goethem, I.F.J. Vankelecom, Recent developments in thin film (nano)composite membranes for solvent resistant nanofiltration, Curr. Opin. Chem. Eng. 8 (2015) 45-54. 
[2] P. Vandezande, L.E.M. Gevers, I.F.J. Vankelecom, Solvent resistant nanofiltration: separating on a molecular level, Chem. Soc. Rev. 37 (2008) 365-405.

[3] J.E. Cadotte, R.J. Petersen, R.E. Larson, E.E. Erickson, NEW THIN-FILM COMPOSITE SEAWATER REVERSE-OSMOSIS MEMBRANE, Desalination. 32 (1980) 25-31.

[4] B.H. Jeong, E.M.V. Hoek, Y.S. Yan, A. Subramani, X.F. Huang, G. Hurwitz, A.K. Ghosh, A. Jawor, Interfacial polymerization of thin film nanocomposites: A new concept for reverse osmosis membranes, J. Membr. Sci. 294 (2007) 1-7.

[5] K. Vanherck, A. Aerts, J. Martens, I. Vankelecom, Hollow filler based mixed matrix membranes, Chem. Commun. 46 (2010) 2492-2494.

[6] M. Peyravi, M. Jahanshahi, A. Rahimpour, A. Javadi, S. Hajavi, Novel thin film nanocomposite membranes incorporated with functionalized $\mathrm{TiO} 2$ nanoparticles for organic solvent nanofiltration, Chem. Eng. J. 241 (2014) 155-166.

[7] S. Roy, S.A. Ntim, S. Mitra, K.K. Sirkar, Facile fabrication of superior nanofiltration membranes from interfacially polymerized CNT-polymer composites, J. Membr. Sci. 375 (2011) 81-87.

[8] M. Namvar-Mahboub, M. Pakizeh, S. Davari, Preparation and characterization of UZM5/polyamide thin film nanocomposite membrane for dewaxing solvent recovery, J. Membr. Sci. 459 (2014) 22-32.

[9] S. Sorribas, P. Gorgojo, C. Tellez, J. Coronas, A.G. Livingston, High Flux Thin Film Nanocomposite Membranes Based on Metal-Organic Frameworks for Organic Solvent Nanofiltration, J. Am. Chem. Soc. 135 (2013) 15201-15208.

[10] C. Echaide-Górriz, S. Sorribas, C. Téllez, J. Coronas, MOF nanoparticles of MIL-68(AI), MIL$101(\mathrm{Cr})$ and ZIF-11 for thin film nanocomposite organic solvent nanofiltration membranes, RSC Adv. 6 (2016) 90417-90426.

[11] L. Sarango, L. Paseta, M. Navarro, B. Zornoza, J. Coronas, Controlled deposition of MOFs by dip-coating in thin film nanocomposite membranes for organic solvent nanofiltration, J. Ind. Eng. Chem. 59 (2018) 8-16.

[12] C. Van Goethem, R. Verbeke, S. Hermans, R. Bernstein, I.F.J. Vankelecom, Controlled positioning of MOFs in interfacially polymerized thin-film nanocomposites, J. Mater. Chem. A. 4 (2016) 16368-16376.

[13] M. Navarro, J. Benito, L. Paseta, I. Gascon, J. Coronas, C. Tellez, Thin-Film Nanocomposite Membrane with the Minimum Amount of MOF by the Langmuir-Schaefer Technique for Nanofiltration, Acs Appl. Mater. Interfaces. 10 (2018) 1278-1287.

[14] F.M. Xiang, A.M. Marti, D.P. Hopkinson, Layer-by-layer assembled polymer/MOF membrane for H-2/CO2 separation, J. Membr. Sci. 556 (2018) 146-153.

[15] L.Y. Wang, M.Q. Fang, J. Liu, J. He, J.D. Li, J.D. Lei, Layer-by-Layer Fabrication of HighPerformance Polyamide/ZIF-8 Nanocomposite Membrane for Nanofiltration Applications, ACS Appl. Mater. Interfaces. 7 (2015) 24082-24093.

[16] A. Parthasarathy, C.J. Brumlik, C.R. Martin, G.E. Collins, INTERFACIAL POLYMERIZATION OF THIN POLYMER-FILMS ONTO THE SURFACE OF A MICROPOROUS HOLLOW-FIBER MEMBRANE, J. Membr. Sci. 94 (1994) 249-254.

[17] T.Y. Liu, Z.H. Liu, R.X. Zhang, Y. Wang, B. Van der Bruggen, X.L. Wang, Fabrication of a thin film nanocomposite hollow fiber nanofiltration membrane for wastewater treatment, J. Membr. Sci. 488 (2015) 92-102.

[18] X. An, P.G. Ingole, W.K. Choi, H.K. Lee, S.U. Hong, J.D. Jeon, Enhancement of water vapor separation using ETS-4 incorporated thin film nanocomposite membranes prepared by interfacial polymerization, J. Membr. Sci. 531 (2017) 77-85.

[19] B. Rajaeian, A. Rahimpour, M.O. Tade, S.M. Liu, Fabrication and characterization of polyamide thin film nanocomposite (TFN) nanofiltration membrane impregnated with TiO2 nanoparticles, Desalination. 313 (2013) 176-188.

[20] S. Verissimo, K.V. Peinemann, J. Bordado, Thin-film composite hollow fiber membranes: An optimized manufacturing method, J. Membr. Sci. 264 (2005) 48-55. 
[21] P.G. Ingole, M. Sohail, A.M. Abou-Elanwar, M.I. Baig, J.D. Jeon, W.K. Choi, H. Kim, H.K. Lee, Water vapor separation from flue gas using MOF incorporated thin film nanocomposite hollow fiber membranes, Chem. Eng. J. 334 (2018) 2450-2458.

[22] L. Paseta, D. Antoran, J. Coronas, C. Tellez, 110th Anniversary: Polyamide/Metal-Organic Framework Bilayered Thin Film Composite Membranes for the Removal of Pharmaceutical Compounds from Water, Ind. Eng. Chem. Res. 58 (2019) 4222-4230.

[23] C. Echaide-Gorriz, C. Clement, F. Cacho-Bailo, C. Tellez, J. Coronas, New strategies based on microfluidics for the synthesis of metal-organic frameworks and their membranes, J. Mater. Chem. A. 6 (2018) 5485-5506.

[24] W. Morris, N. He, K.G. Ray, P. Klonowski, H. Furukawa, I.N. Daniels, Y.A. Houndonougbo, M. Asta, O.M. Yaghi, B.B. Laird, A Combined Experimental-Computational Study on the Effect of Topology on Carbon Dioxide Adsorption in Zeolitic Imidazolate Frameworks, J. Phys. Chem. C. 116 (2012) 24084-24090.

[25] M.M. Sprung, A summary of the reactions of aldehydes with amines, Chem. Rev. 26 (1940) 297-338.

[26] F. Cacho-Bailo, G. Caro, M. Etxeberria-Benavides, O. Karvan, C. Tellez, J. Coronas, High selectivity ZIF-93 hollow fiber membranes for gas separation, Chem. Commun. 51 (2015) $11283-11285$.

[27] F. Cacho-Bailo, B. Seoane, C. Tellez, J. Coronas, ZIF-8 continuous membrane on porous polysulfone for hydrogen separation, J. Membr. Sci. 464 (2014) 119-126.

[28] K.S. Elvira, X.C.I. Solvas, R.C.R. Wootton, A.J. deMello, The past, present and potential for microfluidic reactor technology in chemical synthesis, Nat. Chem. 5 (2013) 905-915.

[29] F. Cacho-Bailo, G. Caro, M. Etxeberria-Benavides, O. Karvan, C. Tellez, J. Coronas, MOFpolymer enhanced compatibility: post-annealed zeolite imidazolate framework membranes inside polyimide hollow fibers, Rsc Adv. 6 (2016) 5881-5889.

[30] J.T. Duan, Y.C. Pan, F. Pacheco, E. Litwiller, Z.P. Lai, I. Pinnau, High-performance polyamide thin-film-nanocomposite reverse osmosis membranes containing hydrophobic zeolitic imidazolate framework-8, J. Membr. Sci. 476 (2015) 303-310.

[31] B.P. Biswal, T. Panda, R. Banerjee, Solution mediated phase transformation (RHO to SOD) in porous Co-imidazolate based zeolitic frameworks with high water stability, Chem. Commun. 48 (2012) 11868-11870.

[32] X.L. Liu, Y.S. Li, Y.J. Ban, Y. Peng, H. Jin, W.S. Yang, K. Li, Synthesis of zeolitic imidazolate framework nanocrystals, Mater. Lett. 136 (2014) 341-344.

[33] K.G. Ray, D.L. Olmsted, J.M.R. Burton, Y. Houndonougbo, B.B. Laird, M. Asta, Gas Membrane Selectivity Enabled by Zeolitic Imidazolate Framework Electrostatics, Chem. Mater. 26 (2014) 3976-3985.

[34] Z.W. Jiang, S. Karan, A.G. Livingston, Water Transport through Ultrathin Polyamide Nanofilms Used for Reverse Osmosis, Adv. Mater. 30 (2018) 7.

[35] N. Hara, M. Yoshimune, H. Negishi, K. Haraya, S. Hara, T. Yamaguchi, Diffusive separation of propylene/propane with ZIF-8 membranes, J. Membr. Sci. 450 (2014) 215-223.

[36] F. Cacho-Bailo, S. Catalan-Aguirre, M. Etxeberria-Benavides, O. Karvan, V. Sebastian, C. Tellez, J. Coronas, Metal-organic framework membranes on the inner-side of a polymeric hollow fiber by microfluidic synthesis, J. Membr. Sci. 476 (2015) 277-285.

[37] A.J. Brown, N.A. Brunelli, K. Eum, F. Rashidi, J.R. Johnson, W.J. Koros, C.W. Jones, S. Nair, Interfacial microfluidic processing of metal-organic framework hollow fiber membranes, Science. 345 (2014) 72-75.

[38] A.M. Marti, W. Wickramanayake, G. Dahe, A. Sekizkardes, T.L. Bank, D.P. Hopkinson, S.R. Venna, Continuous Flow Processing of ZIF-8 Membranes on Polymeric Porous Hollow Fiber Supports for CO2 Capture, Acs Appl. Mater. Interfaces. 9 (2017) 5678-5682.

[39] F. Cacho-Bailo, M. Etxeberria-Benavides, O. Karvan, C. Tellez, J. Coronas, Sequential amine functionalization inducing structural transition in an aldehyde-containing zeolitic 
imidazolate framework: application to gas separation membranes, Crystengcomm. 19 (2017) 1545-1554.

[40] C. Van Goethem, R. Verbeke, M. Pfanmoller, T. Koschine, M. Dickmann, T. Timpel-Lindner, W. Egger, S. Bals, I.F.J. Vankelecom, The role of MOFs in Thin-Film Nanocomposite (TFN) membranes, J. Membr. Sci. 563 (2018) 938-948.

[41] L. Lin, C. Feng, R. Lopez, O. Coronell, Identifying facile and accurate methods to measure the thickness of the active layers of thin-film composite membranes - A comparison of seven characterization techniques, J. Membr. Sci. 498 (2016) 167-179. 
Appendix A - Figures

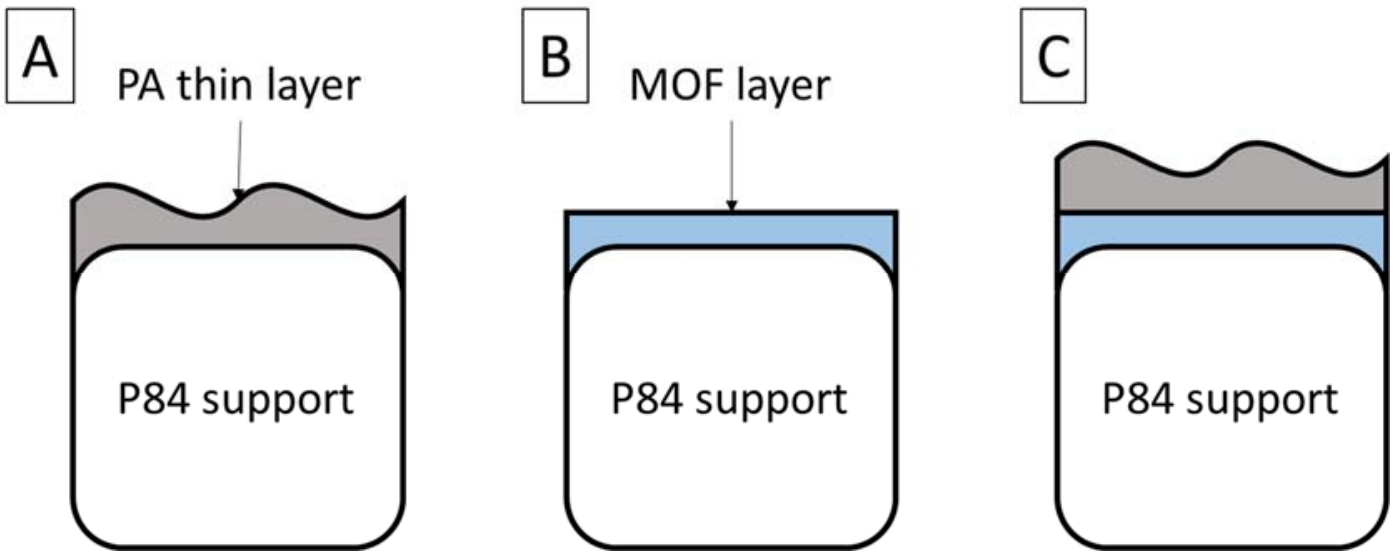

Fig. A6. Structures of the three membranes synthesized: the TFC membrane, composed by the polyimide $P 84^{\circledR}$ support and the PA thin film, with an estimated average surface roughness value of $15 \mathrm{~nm}$ [22] (A); the MOF-based membrane, composed by a continuous MOF layer formed on the polyimide $P 84^{\circledR}$ support (B); and the double layer PA-MOF; formed by the PA thin film over the MOF layer, synthesized on the polyimide $P 84^{\circledR}$ support, with an estimated average roughness value of $38 \mathrm{~nm}[22]$ (C). 


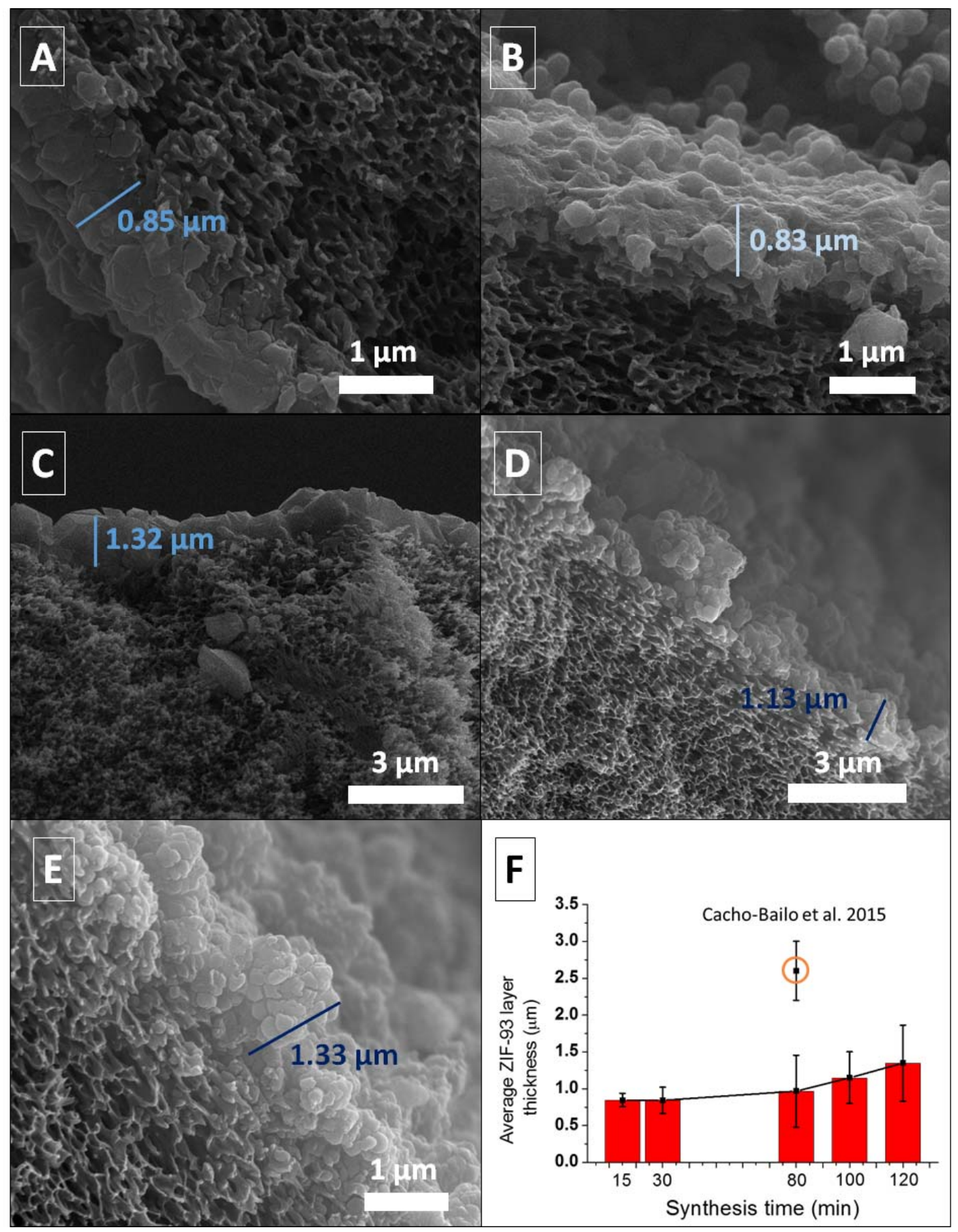

Fig. A7. Cross-section of MOF-based hollow fiber membranes with synthesis times of $15 \mathrm{~min}(\mathrm{~A}), 30 \mathrm{~min}(\mathrm{~B}), 80 \mathrm{~min}$ (C), $100 \mathrm{~min}(D)$ and $120 \mathrm{~min}$ (E). Thicknesses obtained from the SEM images (F). Value of Cacho-Bailo et al. 2015 obtained from [26]. 


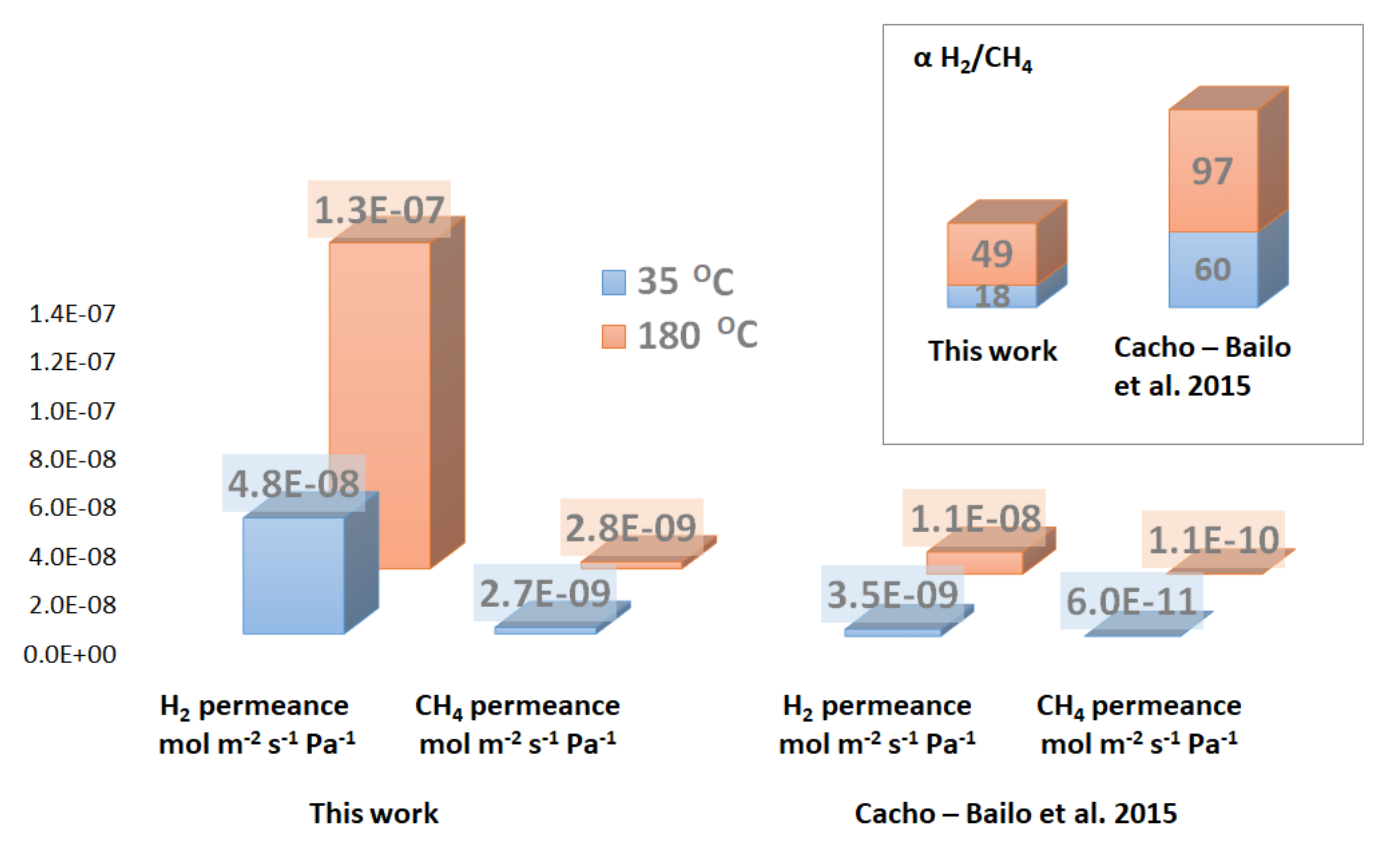

Fig. A8. $\mathrm{H}_{2} / \mathrm{CH}_{4}$ permeation comparison, carried out at 35 and $180{ }^{\circ} \mathrm{C}$, between the ZIF-93-based hollow fiber membrane synthesized here during 120 min and the ZIF-93 based hollow fiber membrane synthesized by Cacho-Bailo et al. [26] during $80 \mathrm{~min}$. 


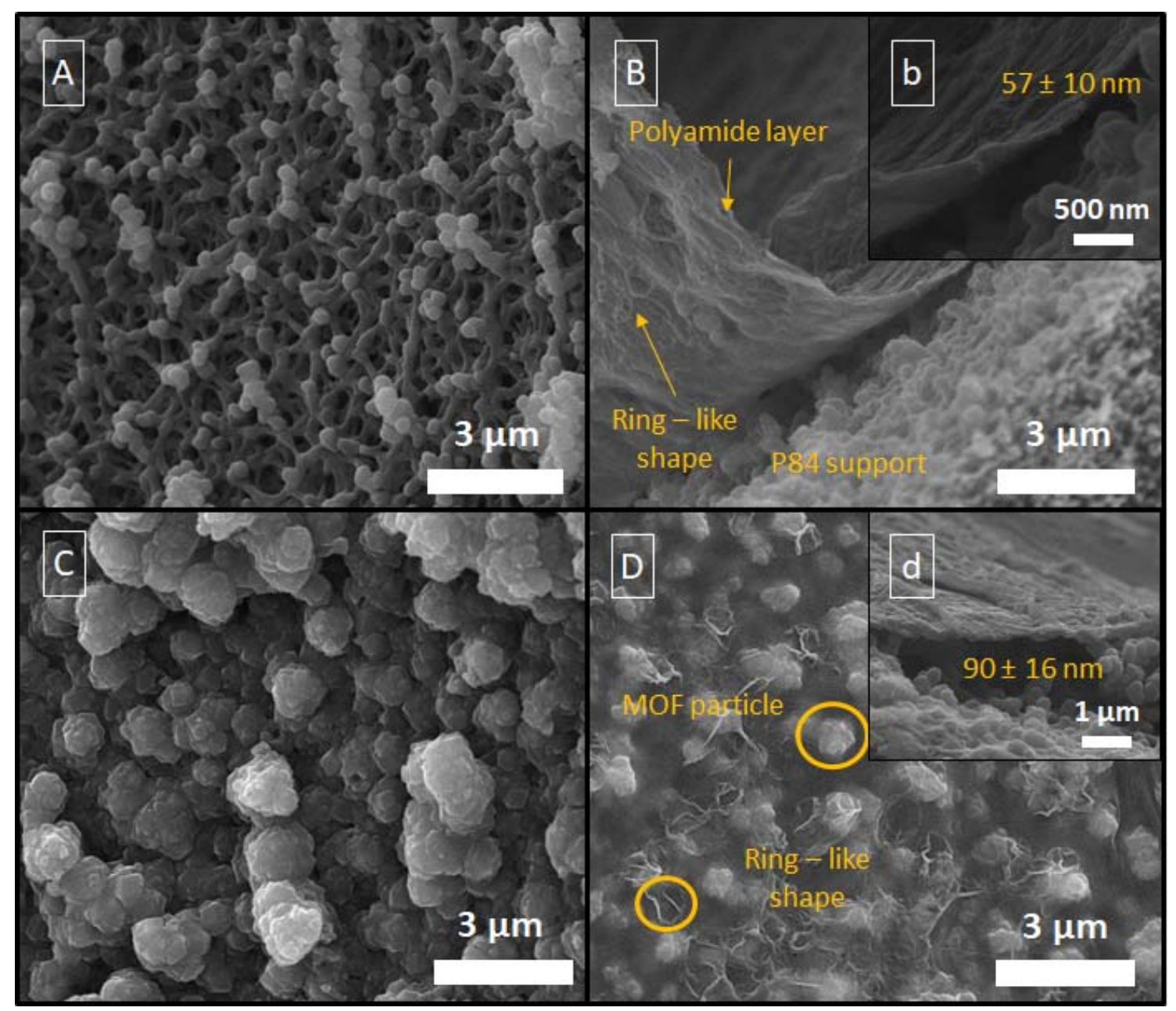

Fig. A9. Bare P84 ${ }^{\circledR}$ hollow fiber support inner surface (A); TFC membrane with the PA thin film synthesized on the lumen side of the polyimide $P 84^{\circledR}$ support (B) and a view in higher magnification of the thin layer cross-section with its average thickness indicated (b); MOF-based membranes supported on the inner surface of the P84 ${ }^{\circledR}$ support (C), and double layer PA-MOF membrane supported on the inner surface of the P84 ${ }^{\circledR}$ support $(D)$, where the same MOF layer observed in C is covered by a continuous PA layer. In the inset, the cross-section is observed and the average PA thin film thickness is indicated (d). 


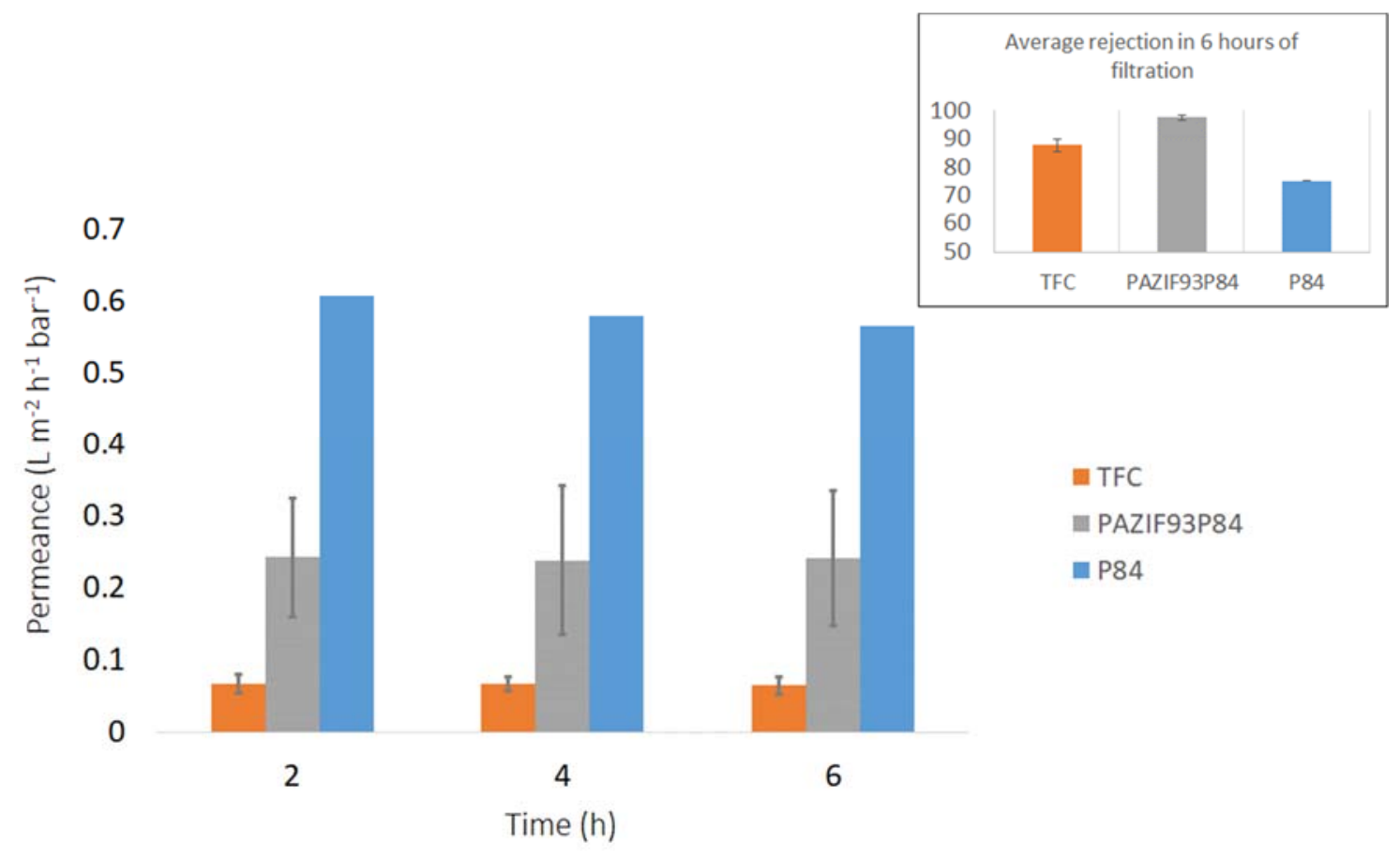

Fig. A10. Nanofiltration performances of the TFC membrane (orange), double - layer PA-ZIF-93, with the MOF layer synthesized in 15 min (grey), and bare P84 ${ }^{\circledR}$ support (blue) in a SY-water solution filtration (see the ZIF-93-based membrane performance in Fig. S3). The main graph shows the permeability of each type of membrane vs the hours of filtration. The graph at the top (inset) shows the average rejection of the solute during the $6 \mathrm{~h}$ of the permeability test for each type of membrane.

Appendix B - Equations

$$
\begin{gathered}
\text { Permeance }=\frac{Q}{\Delta P}=\frac{V}{A \cdot t \cdot \Delta P} \quad(\text { Equation B1) } \\
\text { Rejection }(\%)=\left(1-\frac{C_{\text {permeate }}}{C_{\text {feed }}}\right) \cdot 100 \quad \text { (Equation B2) }
\end{gathered}
$$

Appendix C - Tables

Table $\mathrm{C} 2 . \% \mathrm{C} / \% \mathrm{~N}$ and $\% \mathrm{O} / \% \mathrm{~N}$ ratios obtained through the quantification of $\mathrm{C}, \mathrm{N}$ and $\mathrm{O}$ elements in XPS of the surface of the bilayered membrane PA-ZIF93 and the TFC membrane. The surfaces considered were of $110 \times 110 \mu m^{2}$

\begin{tabular}{|c|c|c|}
\hline Membrane & $\% \mathrm{C} / \% \mathrm{~N}$ & $\% \mathrm{O} / \% \mathrm{~N}$ \\
\hline PA-ZIF93-P84 & $6.2 \pm 0.6$ & $1.2 \pm 0.1$ \\
\hline TFC & $6.9 \pm 0.7$ & $1.3 \pm 0.1$ \\
\hline
\end{tabular}

